RESEARCH

\title{
14-3-3E Has No Homology to LIS1 and Lies Telomeric to It on Chromosome 17p13.3 Outside the Miller-Dieker Syndrome Chromosome Region
}

\author{
Samuel S. Chong, ${ }^{1,2}$ Akira Tanigami, ${ }^{1}$ Anna V. Roschke, ${ }^{1}$ and \\ David H. Ledbetter ${ }^{1,3}$
}

\author{
'National Center for Human Genome Research, National Institutes of Health, Bethesda, Maryland \\ 20892; ${ }^{2}$ Department of Pediatrics, Georgetown University Medical Center, Washington, D.C. 20007
}

\begin{abstract}
Previously, we isolated several cDNA clones of the LISI gene implicated in Miller-Dieker syndrome. Analysis of the $5^{\prime}$ end of one of the clones (8-1), which was originally thought to represent the $5^{\prime}$ end of $L I S 1$, indicates

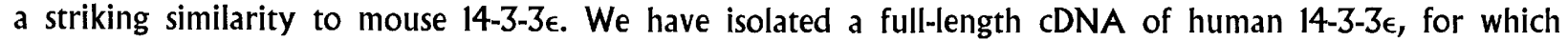
sequence analysis reveals a strong nucleotide conservation with mouse 14-3-3 $\epsilon$ in both translated and untranslated regions (UTRs). Additionally, the predicted peptides of human, sheep, rat, and mouse 14-3-3 $\epsilon$ are identical. Using a 205-bp fragment common to LISI (8-1) and $14-3-3 \epsilon$ as probe on adult and fetal multiple-tissue Northern blots, a $\sim 2-\mathrm{kb}$ transcript is detected, identical to the pattern observed with a full-length 14-3-3€ cDNA probe. LISI-specific transcripts of $\sim 7.5$ and $\sim 5 \mathrm{~kb}$ are not detected by the $0.2-\mathrm{kb}$ probe, indicating that the similarity between the $5^{\prime}$ sequence of LISI (8-1) and the $3^{\prime}$ UTR of 14-3-3 $\epsilon$ is not the result of shared homology between the two genes. Instead, clone 8-1 is a chimera of 14-3-3€ and LISI partial cDNAs, and therefore its $5^{\prime}$ sequence does not represent the LISI $5^{\prime}$ end. Interestingly, we have mapped the 14-3-3E gene to the same chromosomal sub-band as LISI (17pl3.3). However, 14-3-3€ lies telomeric to LISI and outside the Miller-Dieker syndrome chromosome region but in a region frequently deleted in several types of cancer, and is a reasonable candidate tumor suppressor gene.
\end{abstract}

Type 1 (classical) lissencephaly is a brain malformation characterized by a smooth cerebral surface and incomplete neuronal migration in the cerebral cortex (Dobyns 1987). Referred to as isolated lissencephaly sequence (ILS) when it occurs as an isolated birth defect, it may also occur with other recognizable congenital anomalies in the case of Miller-Dieker syndrome (MDS). Both ILS and MDS have been localized to $17 \mathrm{p} 13.3$, and we recently identified a gene, LIS1, which was shown to be deleted in several patients (see Dobyns et al. 1993; Reiner et al. 1993, and references therein).

One of the LIS1 cDNAs isolated in the original study (clone 8-1) contains a sequence at its $5^{\prime}$ end that was thought to represent the most $5^{\prime}$ end of the gene (Reiner et al. 1993). However, this sequence also shares significant sequence

${ }^{3}$ Corresponding author.

E-MAIL dhI@babies.bsd.uchicago.edu; FAX (312) 834-0505. similarity to part of the mouse $14-3-3 \epsilon 3^{\prime}$ untranslated region (UTR) (McConnell et al. 1995). To facilitate further investigation into the relationship between LIS1 and 14-3-3€, we identified a full-length human 14-3-3€ cDNA clone through matches with expressed sequence tags (ESTs) deposited in the GenBank data base, which was then completely sequenced.

We present data to show that there is no homology between LIS1 and 14-3-3€, and that clone 8-1 is a chimeric cDNA. We have also mapped 14-3-3€ telomeric to LIS1, outside the MDS chromosome region, suggesting that it is not involved in either the lissencephaly or the facial dysmorphism phenotypes of MDS.

\section{RESULTS}

Sequence Analysis of LISI and 14-3-3€ CDNAs

Previously, we isolated four cDNAs of LIS1, with clones 47 and 71 containing the complete open 


\section{CHONG ET AL.}

reading frame, but none were full-length based on the $7.5-\mathrm{kb}$ size of the largest LIS1 transcript (Reiner et al. 1993, 1995). One of the other two cDNAs (clone 8-1) contains a 5' sequence not shared by the other clones and was originally thought to contain the 5' end of LIS1 (Reiner et al. 1993). However, this same sequence also exhibits significant similarity to part of the mouse 14-3-3€ 3' UTR (GenBank accession no. Z19599), raising the possibility that LIS1 and 14-3-3€ may belong to a gene family. To investigate this possibility further, we first performed a BLAST search of GenBank using mouse 14-3-3€ cDNA sequence and identified a human EST with a high scoring match (GenBank accession no. T73523). We then obtained the cDNA clone containing this EST (clone 82702) for complete sequence determination.

Sequence analysis reveals this clone to be $1726 \mathrm{bp}$ in length excluding the poly(A) tail (38 nucleotides), with the first nucleotide of the AATAAA polyadenylation signal occurring $19 \mathrm{bp}$ upstream at position 1708 (Fig. 1A). A 60nucleotide 5' UTR is followed by an open reading frame encoding a peptide of 255 amino acids and a 3' UTR of 898 nucleotides before the poly(A) tail. Alignment against mouse 14-3-3€ cDNA confirms that clone 82702 is human 14$3-3 \epsilon$, there being a high degree of nucleotide conservation across both translated and untranslated regions between the two species. Most strikingly, the predicted peptides of human, sheep (GenBank accession no. L07914), rat (GenBank accession nos. M84416 and D30739), and mouse $14-3-3 \epsilon$ are completely conserved (100\% identity). In contrast, other isoforms of 14-3-3 for which human and rat peptide sequences are available in GenBank show $<100 \%$ interspecies conservation. Using the LipmanPearson alignment function in the DNASTAR program, human versus rat similarity indices of $98.4,99.6,99.2$, and 99.6 were obtained for the $\beta$, $\theta, \eta$, and $\zeta$ 14-3-3 isoforms, respectively. Pair-wise analyses also indicate strong homologies among the different human 14-3-3 isoforms and even stronger homologies between human $14-3-3 €$ isoform and the yeast 14-3-3 genes (Table 1).

Alignment analysis also reveals a $99.7 \%$ identity between nucleotide 1207 and 1565 of human 14-3-3 $\epsilon$ and nucleotide 3 and 313 of LIS1(8-1), a match of 310 of 311 nucleotides (Fig. 1A). While this study was in progress, Conklin et al. (1995) reported the isolation of another human 14-3-3€ clone through functional interaction with CDC25 phosphatases in a yeast two-hybrid system. However, this clone lacks the final 687 nucleotides of the 3' UTR ending at the polyadenylation signal, within which the segment similar to LIS1(8-1) is found. Detailed comparison of these two cDNAs and sequence obtained from cosmid 141E2, which contains most of the 14-3$3 \epsilon$ gene, revealed the presence of several sequence polymorphisms (Fig. 1B).

\section{Northern Analyses}

We reasoned that if the common sequence shared by LIS1(8-1) and 14-3-3€ represents an integral part of both the LIS1 and 14-3-3€ genes, LIS1-specific transcripts of $\sim 7.5$ and $\sim 5 \mathrm{~kb}$ (Reiner et al. 1995) and a 14-3-3€-derived transcript (or transcripts) should be detected by it. To test this premise, we performed a Northern blot analysis using a 205-bp fragment common to LIS1(8-1) and $14-3-3 \epsilon$ (probe A). Using this probe, a single transcript of $\sim 2 \mathrm{~kb}$ is clearly seen in all fetal and adult tissues tested (Fig. 2), with the exception of peripheral blood leukocytes where the result was unclear (not shown). No other transcripts were detected with this probe, even upon longer ex-

\begin{tabular}{|c|c|c|c|c|c|}
\hline & h14-3-3e & sprad24 & scBMH2 & scBMH1 & sprad 25 \\
\hline h14-3-3e & 100.0 & 76.8 & 73.0 & 72.7 & 70.0 \\
\hline 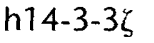 & 67.3 & 68.5 & 64.4 & 63.5 & 64.3 \\
\hline 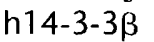 & 66.2 & 64.0 & 62.5 & 62.2 & 62.2 \\
\hline h14-3-30 & 65.0 & 61.3 & 61.2 & 64.2 & 60.0 \\
\hline h14-3-3n & 61.9 & 63.2 & 61.1 & 60.6 & 59.6 \\
\hline
\end{tabular}

(h) Human; (sp) Schizosaccharomyces pombe; (sc) Saccharomyces cerevisiae. Values for comparisons of h14-3-3e to the other human 14-3-3 isoforms and to the yeast proteins are in bold. 
A

\begin{tabular}{|c|c|}
\hline $\begin{array}{ccccccccccccccccccc}M & \mathrm{D} & \mathrm{D} & \mathrm{R} & \mathrm{E} & \mathrm{D} & \mathrm{L} & \mathrm{V} & \mathrm{Y} & \mathrm{Q} & \mathrm{A} & \mathrm{K} & \mathrm{L} & \mathrm{A} & \mathrm{E} & \mathrm{Q} & \mathrm{A} & \mathrm{E} & \mathrm{R}\end{array}$ & \\
\hline $\begin{array}{l}D \\
\text { BACGAAATGGTGGAGTCAATGAAGAAAGTAGCAGGGATGGATGTGGAGCTGACAGTTGAA }\end{array}$ & \\
\hline 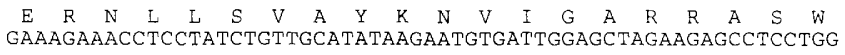 & \\
\hline 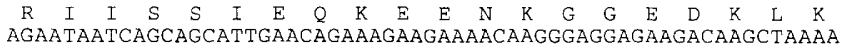 & \\
\hline $\begin{array}{l}M \\
\text { MTGATTCGGGAATATCGGCAAATGGTTGAGACTGAGCTAAAGTTAATCTGTTGTGACATT }\end{array}$ & \\
\hline $\begin{array}{l}\mathrm{L} \\
\text { CTGGATGTACTGGACAAACACCTCATTCCAGCAGCTAACACTGGCGAGTCCAAGGTTTTC }\end{array}$ & \\
\hline $\begin{array}{ccccccccccccccccccc}Y & Y & K & M & K & G & D & Y & H & R & Y & L & A & E & F & A & T & G & N \\
\text { TATTATAAAATGAAAGGGGACTACCACAGGTATCTGGCAGAATTTGCCACAGGAAACGAC }\end{array}$ & \\
\hline $\begin{array}{l}\mathrm{R} \\
\text { AGGAAGGAGGCTGCGGAGAACAGCCTAGTGGCTTATAAAGCTGCTAGTGATATTGCAATG }\end{array}$ & \\
\hline 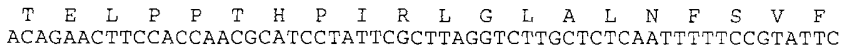 & \\
\hline 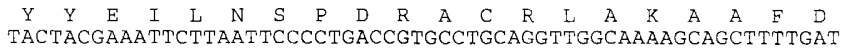 & \\
\hline$\underset{\text { GATGCAATTGCAGAACTGGATACGCTGAGTGAAGAAAGCTATAAGGACTCTACACTTATC }}{\mathrm{D}}$ & \\
\hline 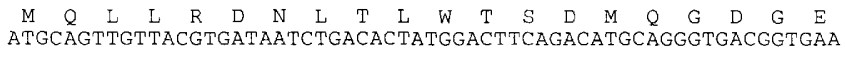 & \\
\hline $\begin{array}{l}E \\
\text { GAGCAGAATAAAGAAGCGCTGCAGGACGTGGAAGACGAAAATCAG TGAga }\end{array}$ & \\
\hline cagagaaaccatctctgaccaccccetcctccccatcccaccctttgga & \\
\hline gtcactgagaaccaccaaatctgacttttacatttggtctcagaatttaggt & 96 \\
\hline tgttggttttttettttttttttaaacagttttcaaagttcttaa & \\
\hline tttaggtt & \\
\hline agaggcttttcagcattactgtgtcgtctccgtgccagatgtggca & \\
\hline tagcaaatggaaattacatttgaaagccattagacttataggtgatgcaa & 120 \\
\hline raggttaatcacactatagaggcataagtggtatcagttttcattttctaat & 126 \\
\hline gactgtgttttataccagt & \\
\hline$g c t$ & \\
\hline ggtaacagttcaacaatccgtggo & \\
\hline at at c c CaO & 50 \\
\hline & 156 \\
\hline gttcagtat & 1 \\
\hline Cag & \\
\hline & \\
\hline
\end{tabular}

\section{B}

$20 \quad 91 \quad 110 \quad 211$

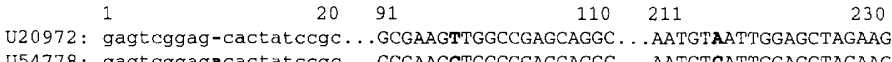
U54778: gagtcggagacactatccgC...GCGAAGCTGGCCGAGCAGGC...AATGTGATTGGAGCTAGAAG c141E2: gagtcggagacactatccgc...GCGAAGCTGGCCGAGCAGGC... (not sequenced)

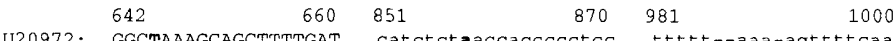
454778: c141E2: GGCAAAAGCAGCTTTTGAT...catctctgaccaccccetcc...ttttt--aaacagttt

U20972: $\begin{array}{lr}1096 & 1115 \\ \text { agcattactatgtcgtctcc }\end{array}$

U54778: agcattactgtgtegtctcc

c141E2: agcattactatgtcgtctcc

Figure 1 (A) Sequence of human 14-3-3€ CDNA clone 82702. Coding nucleotides are capitalized, the translation stop codon is indicated by asterisks, and the polyadenylation signal is doubly underlined. Predicted amino acids are shown in single-letter code and capitalized. 3' UTR sequences not found in the Conklin et al. (1995) clone are italicized and begin from position 1027. The identical sequence found on LIS1 CDNA clone 8-1 is underlined. $(B)$ Sequence polymorphisms within the untranslated and coding regions of human 14-3-3€. Nucleotide positions are according to the numbering in $A$. Top row sequences are from Conklin et al. (1995), middle row sequences are from this study, and bottom row sequences are from cosmid 141E2. Coding sequences are capitalized, and sequence differences are in boldface type. posure of these blots. An identical result was obtained when the blots were stripped and rehybridized with the full-length 14-3$3 \epsilon$ cDNA (data not shown). These results indicate that the $-2-\mathrm{kb}$ transcript is $14-3-3 \mathrm{e}-$ specific and that the $5^{\prime}$ fragment of LIS1(81 ) in common with $14-3-3 \epsilon$ does not represent the $5^{\prime}$ end of the LIS1 gene. Coupled with the fact that the LIS1(8-1) sequence appears truncated and has an incomplete reading frame, we conclude that LIS1 clone 8-1 is a chimera of partial 14-3-3€ and LIS1 cDNA sequences and that there is no homology between the two genes.

\section{Chromosomal Mapping}

Using a full-length 14-3-3€ cDNA as probe on a PstI-digested panel of monochromosomal human-rodent somatic cell hybrid DNAs, multiple human-specific bands are detected for chromosome 17 , a strongly hybridizing $\sim 4.4-\mathrm{kb}$ band is also present for chromosome 7 , and a weak -3.8 -kb band is seen for both chromosomes 1 and 2 (data not shown). Hybridization with the 205-bp probe A redetects a $1.45-\mathrm{kb}$ fragment for chromosome 17 only (data not shown), indicating that the $14-3-3 \epsilon$ gene maps to chromosome 17 and that homologous sequences are present on chromosome 7 and possibly on chromosomes 1 and 2 .

To confirm and further localize the 14 $3-3 \epsilon$ gene on chromosome 17 , we performed PCR analysis on a chromosome 17 regional mapping panel of somatic cell hybrids, each containing a different partially deleted chromosome 17 . Because of the high sequence similarities in the human, mouse, and rat 14-3-3€ cDNAs, the use of purely cDNA-derived primers results in amplification of the rodent background (data not shown). Also, because homologous sequences are present on several other human chromosomes, the fact that each hybrid cell contains other human chromosomes in addition to the partial 17 causes ambiguous PCR results to be obtained when using such primers. To overcome these problems, we sequenced the exon $1 /$ intron 1 junction of 14-3-3€ using c141E2 and designed a primer pair to amplify a 173-bp fragment spanning this junction. Using this primer pair, the expected frag- 
CHONG EI AL.
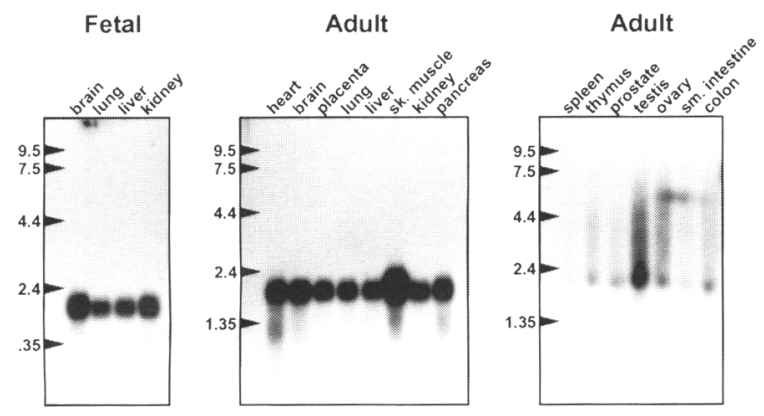

Figure 2 Northern blot analysis of human fetal and adult tissues probed with a partial cDNA fragment present in both 14-3-3€ and LIS1(8-1) cDNAs (nucleotides 1221-1425 of 14-3-3€ sequence in Fig. 1 and nucleotides 17-221 of LIS1 clone 8-1 sequence). Marker sizes are in kilobases.

ment could be amplified from total human genomic DNA and from a human-rodent hybrid containing only human chromosome 17 but not from any of the rodent DNAs nor from any of the non-17 human-rodent hybrids (data not shown). PCR analysis was then performed on the DNAs from the chromosome 17 regional mapping panel, the results of which are summarized in Figure 3. Surprisingly, $14-3-3 \epsilon$ localizes to chromosomal sub-band $17 \mathrm{p} 13.3$, where LIS1 also resides (Fig. 3A). This result has been confirmed by fluorescence in situ hybridization analysis of several cosmids containing the $14-3-3 \epsilon$ gene (69E1, 149G9, 147H7), showing hybridization to distal $17 p$ (data not shown). Further fine mapping using hybrids containing chromosomes 17 with small interstitial deletions in p13.3, however, places $14-3-3 \epsilon$ distal to LIS1 in the third interval from the telomere (Fig. 3B). Southern blot analysis of these hybrid DNAs using probes $A$ and $B$, specific to the $3^{\prime}$ and $5^{\prime}$ ends of the 14-3-3e cDNA, respectively, confirms the position of 143-3€ relative to LIS1 (data not shown). At least two genes have been localized to interval 4 , one at D17S5 and another at D17S379 (Wales et al. 1995; S.S. Chong et al., unpubl.); therefore, 14-3$3 \epsilon$ and LISI are not adjacent genes. Because the telomeric boundary of the MDS chromosome region is defined by the distal deletion breakpoint of patient MDS-9 (Ledbetter et al. 1989), these results suggest that $14-3-3 \epsilon$ is unlikely to be involved in the MDS.

\section{DISCUSSION}

We have shown that clone $8-1$ is a chimera of partial LIS1 and 14-3-3€ cDNAs and that there is no homology between these two genes. Interestingly, we have mapped $14-3-3 \epsilon$ to the same chromosomal sub-band as LIS1, but to a more telomeric locus. The telomeric boundary of the MDS chromosome region is defined by the distal deletion breakpoint of patient MDS-9 (Ledbetter et al. 1989). The placement of $14-3-3 \epsilon$ telomeric to this breakpoint suggests that it is not involved in either the lissencephaly or facial dysmorphism phenotypes of MDS.

Nonetheless, $14-3-3 \epsilon$ is located in a region with frequent loss of heterozygosity in ovarian

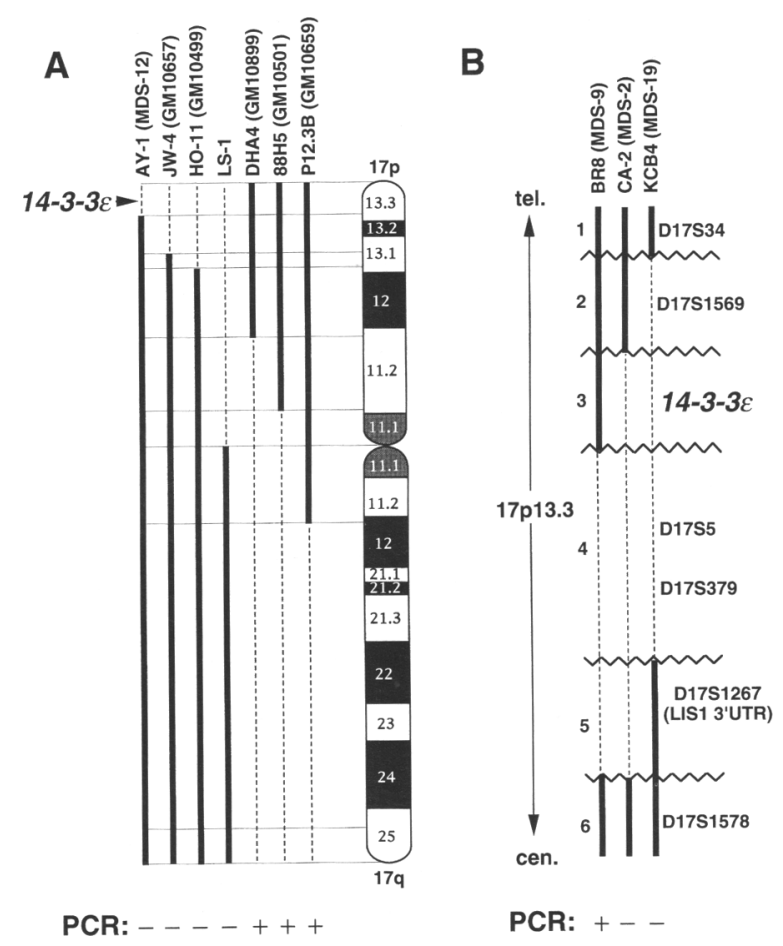

Figure $3(A)$ Schematic representation showing regional localization of 14-3-3€ on chromosome 17 . PCR analysis was performed on hybrid cell lines, each containing a partially deleted chromosome 17 (cell lines available from the Human Genetic Mutant Cell Repository, Camden, NJ, are indicated by their GM catalog number). Primers specifically amplify only the chromosome 17-located gene, and the presence or absence of the expected amplicon is indicated by + or - at the bottom. (B) Position of 14-3-3€ relative to $L / S 1$ within $17 p 13.3$. PCR analysis was performed on hybrid cell lines derived from lymphoblasts of three MDS patients whose deletion breakpoints had been characterized previously. Several D17S markers are indicated to provide reference points within each interval (D17S1267 is derived from the $3^{\prime}$ UTR of LIS1 clone 71). 
cancer (Phillips et al. 1993), medulloblastoma (Cogen et al. 1992; McDonald et al. 1994), astrocytomas (Saxena et al. 1992), bladder cancer (Williamson et al. 1994), neuroectodermal tumors (Biegel et al. 1992), and especially breast cancer (see Nagai et al. 1995; Stack et al. 1995, and references therein). Two genes, $A B R$ and $C R K$, map close to the frequently deleted D17S34 marker and are candidate tumor suppressor genes (Morris et al. 1995). A novel gene, HIC1, maps to another frequently deleted marker, D17S5, and has also been proposed as a candidate tumor suppressor distinct from the $17 \mathrm{p} 13.1$-located $p 53$ gene (Wales et al. 1995). 14-3-3€ lies between D17S5 on the centromeric side and D17S34 on the telomeric side, thus suggesting that it may also be deleted frequently in these cancers.

Although their exact functions are unknown, numerous roles have been assigned to the 14-3-3 proteins (Aitken 1995; Burbelo and Hall 1995). The high degree of peptide homology between the various 14-3-3 isoforms suggests that they may perform overlapping functions. Yet, the absolute or near absolute evolutionary conservation of each 14-3-3 isoform within mammals suggests that the different isoforms may also have essential nonoverlapping functions. Of the various human 14-3-3 isoforms, the 14-3-3€ peptide shares the highest homology with the yeast 143-3 homologs, which have been shown to be essential genes (Ford et al. 1994; Gelperin et al. 1995). In fission yeast, the two 14-3-3 proteins $(\operatorname{rad} 24$ and $\operatorname{rad} 25)$ are both required for DNA damage checkpoint control; mutations in either gene result in premature entry into mitosis, whereas mutations in both genes is lethal (Ford et al. 1994).

It is therefore possible that $14-3-3 \epsilon$ may play a similar role in the mammalian cell cycle, especially in light of a recent report demonstrating a preferential interaction between $14-3-3 \epsilon$ protein and cdc25B phosphatase (Conklin et al. 1995). The cdc25 phosphatases play a key role in the cell cycle, enabling entry into mitosis through activation of cyclin-dependent kinases (Millar and Russell 1992) and have also been proposed as potential human oncogenes, because in addition to the oncogenic cooperation of cdc25A and cdc25B with Ras and an oncogenic effect of cdc $25 \mathrm{~A}$ in fibroblasts lacking the retinoblastoma tumor suppressor RB1, cdc25B phosphatase was overexpressed in $32 \%$ of the primary breast cancers studied (Galaktionov et al. 1995a). Furthermore, cdc25 phosphatase has been shown to associate with Raf and be activated by it, thus directly linking mitogenic signal transduction to the cell cycle (Galaktionov et al. 1995b). Although yet to be experimentally tested, it is possible that 14-3$3 \epsilon$ may act to suppress the oncogenic effect of cdc25B phosphatase.

14-3-3 proteins also interact directly with proto-oncogene and oncogene products such as Raf, a downstream effector of the Ras-mediated signal transduction pathway, (Morrison 1994), and the binding appears to be critical for signal protein activation (Muslin et al. 1996). The 143-3 isoforms exist either as homodimers or heterodimers, and it has been suggested that their composition within a cell may modulate their role in signal transduction and in the cell cycle (Aitken et al. 1995). Given their strong links to both the cell cycle machinery and mitogenic signal transduction pathways, it is tempting to speculate that the 14-3-3 proteins may in fact possess tumor suppressor properties, such that complete loss of one isoform, for example, the $17 \mathrm{p} 13.3$-located $14-3-3 \epsilon$, within a cell may be sufficient to disrupt normal signal transduction and regulated entry into mitosis, leading eventually to neoplastic transformation.

\section{METHODS}

\section{Sequence Analyses}

Similarity searches of GenBank, dbEST, and other data bases were performed using BLAST (Altschul et al. 1990). Sequence alignments and other analyses were accomplished using the DNASTAR program (DNASTAR, Madison, WI).

\section{cDNA and Cosmid Clones}

LIS1 cDNA clones 71, 47, and 8-1 have been described previously (Reiner et al. 1993), and sequences are available in GenBank through accession numbers L13385, L13386, and L13388, respectively.

Clone 82702 contains a full-length human 14-3-3e cDNA inserted $5^{\prime} \rightarrow 3^{\prime}$ into pBluescript $\mathrm{SK}(-)$ at the EcoRI and $X h o I$ sites, respectively. This clone originated from a liver cDNA library (Stratagene, La Jolla, CA) that was obtained from the IMAGE (Integrated Molecular Analysis of Genomes and their Expression) consortium, Lawrence Livermore National Laboratory (Berkeley, CA). Complete sequencing of both strands of this cDNA was performed commercially (SeqWright, Houston, TX), and its sequence has been deposited in GenBank under accession number U54778.

Cosmids 141E2, 69E1, 149G9, and 147H7 contain different portions of the $14-3-3 \epsilon$ gene and were isolated from 


\section{CHONG ET AL.}

a flow-sorted human chromosome 17 gridded library (LA17NC01) constructed at the Los Alamos National Laboratory (Los Alamos, NM), and are available from the Physical Mapping Core, National Center for Human Genome Research, National Institutes of Health. Sequencing of the exon 1/intron 1 junction from cosmid 141E2 was performed manually as described (Sambrook et al. 1989).

\section{DNA Isolation and Probe Synthesis}

DNA from lymphoblastoid cells and somatic cell hybrids was isolated by routine methods (Sambrook et al. 1989) and digested with the restriction enzyme PstI or HindIII according to supplier instructions. Plasmid and cosmid DNAs were isolated using the Qiagen plasmid kit (Qiagen, Chatsworth, CA).

Hybridization probes were PCR amplified from cDNA clones, gel-purified using the Qiaquick gel extraction kit (Qiagen), and labeled to high specific activity with $\left[\alpha{ }^{32} \mathrm{P}\right] \mathrm{dCTP}$ using the DECAprime II random-decamer labeling kit (Ambion, Austin, TX). A primer pair ( $5^{\prime}$ GAGGCATAAGTGGTATCAG-3' and 5'-GGATTGTTGAACTGTTACCAG-3') was used to amplify a 205-bp fragment (probe A) from the $5^{\prime}$ end of LIS1(8-1) that was also present in the $3^{\prime}$ UTR of 14-3-3 $\epsilon$. Another primer pair (5'TATCCGCTTCCATCCGTC-3' and $5^{\prime}$-TGCTGATTATTCTCCAGGAGG-3') was used to amplify a 239-bp fragment (probe B) specific to the $5^{\prime}$ end of $14-3-3 \epsilon$. A full-length probe of $14-3-3 \epsilon$ was generated from clone 82702 by PCR using T3 and T7 primers (Stratagene). Standard Taq polymerase-mediated PCR reactions were performed in a PE480 thermal cycler (Perkin Elmer-ABI), with an initial denaturation at $94^{\circ} \mathrm{C}$ for $2 \mathrm{~min}$, followed by 35 cycles of $94^{\circ} \mathrm{C}$ for $45 \mathrm{sec}, 55^{\circ} \mathrm{C}$ for $1 \mathrm{~min}$, and $72^{\circ} \mathrm{C}$ for 1 min. PCR products were electrophoresed across a $1.5 \%$ agarose gel in $0.5 \times \mathrm{TBE}$ at $10 \mathrm{~V} / \mathrm{cm}$ followed by gel purification and labeling.

\section{Northern Analysis}

Northern analysis of $14-3-3 \epsilon$ was performed using specific fragments or the full-length cDNA clone. Multiple-tissue adult and fetal Northern blots were obtained from a commercial source, and probe hybridizations and blot washes were performed according to manufacturer instructions (Clontech, Palo Alto, CA).

\section{Chromosomal Localization of $14-3-3 \epsilon$}

Initial chromosomal assignment of $14-3-3 \epsilon$ was accomplished by Southern blot hybridization of a full-length 143-3€ cDNA against a panel of PstI-digested monochromosomal human-rodent somatic cell hybrid DNAs (Oncor, Gaithersburg, MD).

Precise localization of $14-3-3 \epsilon$ was accomplished by PCR analysis of DNA from human-rodent somatic cell hybrids, each containing a partial segment of chromosome 17 as described previously (vanTuinen et al. 1987; Ledbetter et al. 1989; Reiner et al. 1993). A forward primer annealing in exon 1 of the 14-3-3 $\epsilon$ gene (5'-AGAGAGTCGGAGACACTATCCG-3') and a reverse primer annealing in intron 1 (5'-GCAGAGGGTCCGAGAATTC-3') were de- signed to amplify a 173-bp fragment specific to the chromosome 17-located gene. Standard Taq polymerasemediated PCR reactions were performed in a PE9600 thermal cycler (Perkin Elmer-ABI, Foster City, CA), with an initial denaturation at $94^{\circ} \mathrm{C}$ for $2 \mathrm{~min}, 35$ cycles of $94^{\circ} \mathrm{C}$ for $30 \mathrm{sec}, 68^{\circ} \mathrm{C}$ for $30 \mathrm{sec}$, and $72^{\circ} \mathrm{C}$ for $1 \mathrm{~min}$, and a final extension at $72^{\circ} \mathrm{C}$ for $5 \mathrm{~min}$. PCR products were separated on a $1.5 \%$ agarose gel in $1 \times \mathrm{TBE}$ at $10 \mathrm{~V} / \mathrm{cm}$. Southern blot analyses of PstI-digested somatic cell deletion hybrid DNAs using probes $\mathrm{A}$ and $\mathrm{B}$ were also performed to confirm the position of $14-3-3 €$ relative to LIS1 within $17 \mathrm{p} 13.3$.

\section{ACKNOWLEDGMENTS}

We thank Dr. Bill Dobyns (Division of Pediatric Neurology, Departments of Neurology and Pediatrics, University of Minnesota Medical School) for reviewing the manuscript. The sequence data described in this paper have been submitted to the GenBank data library under accession number U54778.

The publication costs of this article were defrayed in part by payment of page charges. This article must therefore be hereby marked "advertisement" in accordance with 18 USC section 1734 solely to indicate this fact.

\section{REFERENCES}

Aitken, A. 1995. 14-3-3 proteins on the MAP. Trends Biochem. Sci. 20: 95-97.

Aitken, A., D. Jones, Y. Soneji, and S. Howell. 1995. 14-3-3 proteins: Biological structure and domain structure. Biochem. Soc. Trans. 23: 605-611.

Altschul, S.F., W. Gish, W. Miller, E.W. Myers, and D.J. Lipman. 1990. Basic local alignment search tool. J. Mol. Biol. 215: 403-410.

Biegel, J.A., C.D. Burk, F.G. Barr, and B.S. Emanuel. 1992. Evidence for a $17 p$ tumor related locus distinct from p53 in pediatric primitive neuroectodermal tumors. Cancer Res. 52: 3391-3395.

Burbelo, P.D. and A. Hall. 1995. 14-3-3 proteins: Hot numbers in signal transduction. Curr. Biol. 5: 95-96.

Cogen, P.H., L. Daneshvar, A.K. Metzger, G. Duyk, M.S.B. Edwards, and V.C. Sheffield. 1992. Involvement of multiple chromosome $17 \mathrm{p}$ loci in medulloblastoma tumorigenesis. Am. J. Hum. Genet. 50: 584-589.

Conklin, D.S., K. Galaktionov, and D. Beach. 1995. 14-3-3 proteins associate with cdc25 phosphatases. Proc. Natl. Acad. Sci. 92: 7892-7896.

Dobyns, W.B. 1987. Developmental aspects of lissencephaly and the lissencephaly syndromes. Birth Defects Orig. Artic. Ser. 23: 225-241.

Dobyns, W.B., O. Reiner, R. Carrozzo, and D.H. Ledbetter. 1993. Lissencephaly, a human brain malformation associated with deletion of the LIS1 gene 


\section{CLONING OF HUMAN 14-3,3€ ON 17P13.3}

located at chromosome 17p13. J. Am. Med. Assoc. 270: $2838-2842$.

Ford, J.C., F. Al-Khodairy, E. Fotou, K.S. Sheldrick, D.J.F. Griffiths, and A.M. Carr. 1994. 14-3-3 protein homologs required for the DNA damage checkpoint in fission yeast. Science 265: 533-535.

Galaktionov, K., A.K. Lee, J. Eckstein, G. Draetta, J. Meckler, M. Loda, and D. Beach. 1995a. CDC25 phosphatases as potential human oncogenes. Science 269: 1575-1577.

Galaktionov, K., C. Jessus, and D. Beach. 1995b. Raf1 interaction with cdc 25 phosphatase ties mitogenic signal transduction to cell cycle activation. Genes \& Dev. 9: 1046-1058.

Gelperin, D., J. Weigle, K. Nelson, P. Roseboom, K. Irie, K. Matsumoto, and S. Lemmon. 1995. 14-3-3 proteins: Potential roles in vesicular transport and Ras signaling in Saccharomyces cerevisiae. Proc. Natl. Acad. Sci.

92: 11539-11543.

Ledbetter, D.H., S.A. Ledbetter, P. vanTuinen, K.M. Summers, T.J. Robinson, Y. Nakamura, R. Wolff, R. White, D.F. Barker, M.R. Wallace, F.S. Collins, and W.B. Dobyns. 1989. Molecular dissection of a contiguous gene syndrome: Frequent submicroscopic deletions, evolutionarily conserved sequences, and a hypomethylated "island" in the Miller-Dieker chromosome region. Proc. Natl. Acad. Sci. 86: 5136-5140.

McConnell, J.E., J.F. Armstrong, P.E. Hodges, and J.B. Bard. 1995. The mouse 14-3-3 epsilon isoform, a kinase regulator whose expression pattern is modulated in mesenchyme and neuronal differentiation. Dev. Biol. 169: $218-228$.

McDonald, J.D., L. Daneshvar, J.R. Willert, K. Matsumura, F. Waldman, and P.H. Cogen. 1994. Physical mapping of chromosome 17p13.3 in the region of a putative tumor suppressor gene important in medulloblastoma. Genomics 23: 229-232.

Millar, J.B. and P. Russell. 1992. The cdc25 M-phase inducer: An unconventional protein phosphatase. Cell 68: $407-410$.

Morris, C., S. Benjes, L. Haataja, D.H. Ledbetter, N. Heisterkamp, and J. Groffen. 1995. Spatial organization of $A B R$ and $C R K$ genes on human chromosome band 17p13.3. Oncogene 10: 1009-1011.

Morrison, D. 1994. 14-3-3: Modulators of signalling proteins? Science 266: 56-57.

Muslin, A.J., J.W. Tanner, P.M. Allen, and A.S. Shaw. 1996. Interaction of 14-3-3 with signaling proteins is mediated by the recognition of phosphoserine. Cell 84: 889-897.

Nagai, M.A., A.C. Medeiros, M.M. Brentani, R.R. Brentani, L.A. Marques, S. Mazoyer, and L.M. Mulligan.
1995. Five distinct deleted regions on chromosome 17 defining different subsets of human primary breast tumors. Oncology 52: 448-453.

Phillips, N., M. Ziegler, B. Saha, and F. Xynos. 1993. Allelic loss on chromosome 17 in human ovarian cancer. Int. J. Cancer 54: 85-91.

Reiner, O., R. Carrozzo, Y. Shen, M. Wehnert, F. Faustinella, W.B. Dobyns, C.T. Caskey, and D.H. Ledbetter. 1993. Isolation of a Miller-Dieker lissencephaly gene containing $\mathrm{G}$ protein $\beta$-subunit-like repeats. Nature 364: 717-721.

Reiner, O., I. Bar-Am, T. Sapir, O. Shmueli, R. Carrozzo, E.A. Lindsay, A. Baldini, D.H. Ledbetter, and A. Cahana. 1995. LIS2, gene and pseudogene, homologous to LIS1 (Lissencephaly 1), located on the short and long arms of chromosome 2. Genomics 30: 251-256.

Sambrook, J., E.F. Fritsch, and T. Maniatis. 1989. Molecular cloning: A laboratory manual, 2nd ed. Cold Spring Harbor Laboratory Press, Cold Spring Harbor, NY.

Saxena, A., W.C. Clark, J.T. Robertson, B. Ikejiri, E.H. Oldfield, and I.U. Ali. 1992. Evidence for the involvement of a potential second tumor suppressor gene on chromosome 17 distinct from p53 in malignant astrocytomas. Cancer Res. 52: 6716-6721.

Stack, M., D. Jones, G. White, D.S. Liscia, T. Venesio, G. Casey, D. Crichton, J. Varley, E. Mitchell, J. Heighway, and M. Santibanez-Koref. 1995. Detailed mapping and loss of heterozygosity analysis suggests a suppressor locus involved in sporadic breast cancer within a distal region of chromosome band 17p13.3. Hum. Mol. Genet. 4: 2047-2055.

vanTuinen, P., D.C. Rich, K.M. Summers, and D.H. Ledbetter. 1987. Regional mapping panel for human chromosome 17: Application to neurofibromatosis type 1. Genomics 1: 374-381.

Wales, M.M., M.A. Biel, W. El-Deiry, B.D. Nelkin, J-P. Issa, W.K. Cavenee, S.J. Kuerbitz, and S.B. Baylin. 1995. p53 activates expression of $\mathrm{HIC}-1$, a new candidate tumour suppressor gene on 17p13.3. Nature Med. 1: $570-577$.

Williamson, M.P., P.A. Elder, and M.A. Knowles. 1994. The spectrum of TP53 mutations in bladder carcinoma. Genes Chromosomes Cancer 9: 108-118.

Received April 19, 1996; accepted in revised form June 17, 1996. 


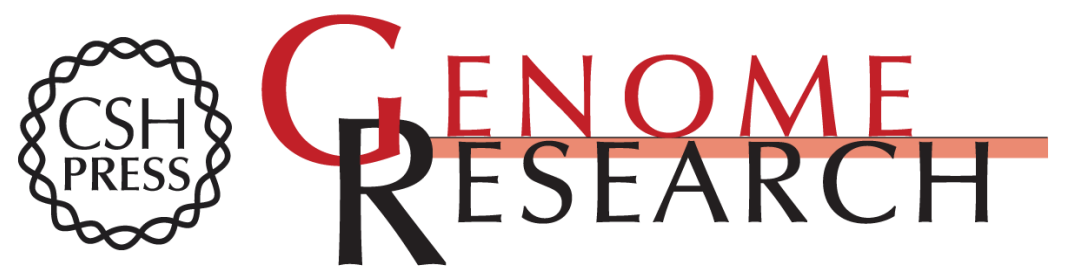

\section{4-3-3 epsilon has no homology to LIS1 and lies telomeric to it on chromosome 17p13.3 outside the Miller-Dieker syndrome chromosome region.}

S S Chong, A Tanigami, A V Roschke, et al.

Genome Res. 1996 6: 735-741

Access the most recent version at doi:10.1101/gr.6.8.735

References This article cites 29 articles, 10 of which can be accessed free at:

http://genome.cshlp.org/content/6/8/735.full.html\#ref-list-1

\section{License}

Email Alerting

Receive free email alerts when new articles cite this article - sign up in the box at the Service top right corner of the article or click here.

\section{Affordable, Accurate Sequencing.}

To subscribe to Genome Research go to: https://genome.cshlp.org/subscriptions 